\title{
SMART TURIZAM - MOGUĆNOST PRIMENE INTERNETA STVARI U SAVREMENOM TURISTIČKOM POSLOVANJU
}

\author{
Ivana Brdar*, \\ Radmila Živković, \\ Jelena Gajić, \\ Jelena Stanković, \\ Nataša Kilibarda
}

Univerzitet Singidunum, Beograd, Srbija

\begin{abstract}
Rezime:
Internet stvari pruža nove mogućnosti zajedničkog delovanja fizičkog i digitalnog sveta. S tim u vezi, on omogućava direktniju i aktivniju interakciju između turista, turističkih proizvoda i destinacija. Turistička industrija je blisko povezana sa, a može se reći i zavisna od, razvoja informacione tehnologije i Interneta. Trenutno, smart turizam pruža pogodnost i interaktivnost i nudi personalizovane usluge turistima. Ovaj rad analizira mogućnosti korišćenja Interneta stvari i tehnologija smart turizma u cilju boljeg razumevanja savremenih aktuelnosti i promena na turističkom tržištu.
\end{abstract}

Ključne reči:

turizam, smart turizam, Internet stvari, informacione tehnologije, Internet.

\section{UVOD}

Savremeno doba donosi brojne promene u svakoj sferi života, samim tim i u poslovanju, posebno kada je reč o turizmu. U globalizovanom i izuzetno dinamičnom okruženju, inovacija je ključni element za sve učesnike u turističkoj ponudi, kako bi se postigla njena konkurentnost. U poslednjim decenijama, tehnološke inovacije, odnosno informacione i komunikacione tehnologije (IKT) su značajno promenile naše društvo u celini. Danas, sa ubrzanim razvojem informacionih i komunikacionih tehnologija, informacije se razmenjuju brže, što znači da turistička preduzeća mogu da iskoriste takvu prednost za povećanje kvaliteta usluga. Kvalitetna usluga predstavlja cilj poslovanja svakog preduzeća, jer kao takva omogućava sticanje lojalnih korisnika usluga i povećanje prihoda. Zbog toga je veoma važna dvosmerna komunikacija, koja bi trebalo da bude zasnovana na razmeni ideja, iskustava i informacija, a čiji su glavni akteri turisti i učesnici na strani turističke ponude.

Turizam predstavlja jednu od delatnosti koja je pretrpela najviše transformacija, posebno otkad su se pojavile Internet stvari - na raspolaganju je višedimenzionalni skup podataka (tzv. Big data) [1]. Napredak ka višoj socijalizaciji IKT-a, pojavu Interneta stvari i Cloud Computing-a učinio je mnogo relevantnijom koncepcijom digitalnog poslovanja, posebno $\mathrm{u}$ oblasti turizma [2].
Odgovorno lice:

Ivana Brdar

e-pošta:

ibrdar@singidunum.ac.rs

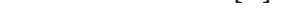


Nova era IKT-a je omogućila upotrebu bogatog spektra novih alata za turističku industriju. Turistička delatnost je pretrpela brojne promene od početka intenzivnog korišćenja informacionih tehnologija u poslovanju. Četiri važna elementa koja imaju uticaj i oblikuju savremeno turističko poslovanje su [3]: (1) digitalizacija i povezanost; (2) ekspanzija Interneta; (3) savremeni oblici posredovanja i (4) prilagođavanje potrebama i očekivanjima potrošača. Danas se turistička preduzeća suočavaju s nizom novih izazova koji proizilaze iz promena na strani turističke tražnje i u okruženju, a koje su nastale pod uticajem nastanka i upotrebe novih tehnologija. Da bi se suočili sa ovim izazovima, preduzeća $i$ učesnici na strani turističke ponude moraju, pre svega, prepoznati vrste promena koje su se desile, a zatim i na njih proaktivno reagovati [4]. Sa turističke perspektive, IKT bi mogle doprineti stvaranju dodatne vrednosti za turiste, a podržavajući automatizaciju procesa za turistička preduzeća poboljšanju njihove efikasnosti [5].

Internet i druge informacione tehnologije u velikoj meri su promenile ponašanje potrošača. $U$ 2017. godini broj korisnika interneta je dostigao skoro 3,6 milijardi u svetu [6]. Ove tehnologije su odigrale ključnu ulogu u turističkoj delatnosti, i to ne samo u vezi sa konkurentnošću preduzeća na strani turističke tražnje, već i po pitanju iskustva turista. Danas, veliki broj transkacija vezanih za putovanja obavlja se preko Interneta. Čak i tokom samog putovanja, Internet, pametni telefoni i druge tehnologije, zbog lake dostupnosti i mogućnosti povezivanja, omogućavaju turistima dostupnost brojnim raznovrsnim i korisnim informacijama.

\section{SMART TURIZAM}

„Smart“ danas predstavlja popularan izraz (inteligentno, pametno) i označava jedan novi vid poslovanja uz korišćenje inteligentnih i informacionih tehnologija. Smart poslovanje uglavnom zahteva i smart analitiku. Glavna podloga integrisanih sistema jeste integraciona i aplikaciona platforma koja objedinjuje korisnike, informacije i poslovne procese [7].

Turistička industrija je sredinom devedesetih godina prošlog veka aktivno prihvatila i počela da upotrebljava Internet kao novi distributivni kanal koji je ubrzo preuzeo vodeću ulogu u poslovanju sa potrošačima. Takođe, Internet se u velikoj meri koristi i kao promotivno sredstvo $[8,9]$. Savremeni turisti su u potpunosti prihvatili korišćenje online alata i može se reći da je, u transakcijama povezanim sa putovanjima, uloga Interneta dosti- gla svoj vrhunac [10]. Upravo te savremene tendencije dovele su do promene viđenja turizma, imajući u vidu upotrebu inteligentnih sistema koji se zasnivaju na upotrebi Big data sistema, što je rezultovalo pojavom novog pojma - smart turizam $[11,12]$.

Termin smart turizam podrazumeva interkonekciju, sinhronizaciju i zajedničku upotrebu različitih tehnologija vezanih za putovanja. Uopšteno govoreći, smart turizam ima za cilj razvijanje informaciono-komunikacione infrastrukture i sposobnosti u cilju poboljšanja upravljanja, olakšavanja inovacija usluga/proizvoda, poboljšanja turističkog iskustva $i$, konačno, poboljšanja konkurentnosti turističkih preduzeća i destinacija $[13,14]$. Korišćenje tehnologija smart turizma, kao što su veb sajtovi, internet portali, veb lokacije povezane sa putovanjem, društveni mediji, i pametni telefoni u planiranju putovanja, značajno se proširilo. Njihov uticaj primećuju i osećaju svi učesnici u turizmu. Iako su se, u početku, tehnologije smart turizma prvenstveno koristile za olakšavanje transakcija i poslovnih operacija, primetno je da se sve veći broj turista okreće ovoj raznolikoj tehnologiji i kanalima kako bi dobili tačnije, sveobuhvatnije i personalizovane informacije u svim fazama planiranja [15]. Imajući u vidu navedeno, nije neobično što se vremenom povećalo i naučno interesovanje za smart turizam. Preciznije, znatan broj istraživanja je fokusiran na upotrebu tehnologija smart turizma tokom planiranja putovanja [16,17].

Brojni autori su počeli da izučavaju ovu koncepciju i to kao: (1) međusobnu povezanost i sinhronizaciju tehnologije i sistema; (2) prilagođen sistem koji se bazira na analizi Big data; i (3) integraciju iskustva turista u fizičko i digitalno okruženje [18].

Nesumnjivo je da se pametni uređaju poput tableta, fableta, pametnih telefona i satova i drugih gedžeta sve više upotrebljavaju u svim fazama turističkog poslovanja, kako na strani ponude, tako i na strani tražnje, u cilju donošenja odluka i raspoloživosti relevantnih i značajnih informacija $[11,19,20]$.

Različite tehnologije koje u interakciji pružaju usluge smart turizma biće internet, mobilne tehnologije, cloud computing, Internet stvari i Big data analize. Tabela 1 sumira ideje smart turizma. 


\section{Ideje smart turizma}

Upotreba senzora, kamera i mobilnih telefona

Upotreba Big data analiza informacija

Kolaboracija veb i moblnih tehnologija i usluga

Upotreba Cloud usluga i Internet stvari

Upotreba ekrana osetljivih na dodir zbog lakše interakcije

Bolja asistencija turistima posredstvom mobilnih tura $\mathrm{i}$ aplikacija

Tabela 1. Ideje smart turizma ${ }^{a}$

Izvor: [33]

Kada kažemo Big data pod time podrazumevamo skup podataka čija veličina prevazilazi mogućnosti standardnih softverskih alatki za upravljanje i upotrebu baza podataka [21]. Ova tehnologija podrazumeva velike količine (Volume) podataka (koji se ne mogu brojčano iskazati i mogu ići i do više petabajtova), koje mogu biti različitih formata (Variety) (teks, slika, video, audio). Takođem one se generišu velikom brzinom (Velocity) na raznim izvorima (veb aplikacije, mobilne aplikacije, senzori, društveni mediji). Pored navedenih " $3 \mathrm{~V}$ " karakteristika Big data, dodate su i: Verodostojnost (Veracity) usled nepouzdanosti i lošeg kvaliteta podataka na Internetu i Vrednost (Value) radi analize ekonomske isplativosti ulaganja u Big data sisteme [22].

Big data analitika predstavlja jedan od savremenih trendova u današnjem poslovanju i ona podrazumeva "primenu naprednih analitičkih tehnika nad skupovima velikih podataka" [22]. Neke od analiza koje se danas sprovode su Sentiment analysis (analiza osećanja ili mišljenja) putem koje se može utvrditi raspoloženje (pozitivno/negativno/neutralno), posebno pri plasiranju novog proizvoda ili usluga ili Evolving topics, što omogućava uvid u teme o kojima se trenutno najviše govori (ko, gde, kada...) [22]. Prednosti upotrebe analitičkih Big data sistema su brojne jer kompanije mogu da: povećaju prihod privlačenjem novih i zadržavanjem postojećih korisnika putem unapređenja prodaje, kreiraju nove proizvode i usluge, kastomizovanog tipa, percipiraju aktuelne trendove i smanje operativne troškove, kreiraju cene u realnom vremenu itd [22].

Međutim, postoje razlozi zašto se u poslovanju turističkih preduzeća Big data analitika ne koristi u dovoljnoj meri. Često se nailazi na nedostatak podrške od strane strateškog menadžmenta i ostalih stejkholdera koji najčešće finansiraju ovakve projekte. Takođe, nedostatak je i u dovoljno obučenim kadrovima koji bi trebalo da rukovode ovakvim sistemima, kao i nedovoljno razvijenim rešenjima na tržištu, u kontekstu pokrivenosti poslovanja određenih delatnosti koje imaju specifičnosti u funkcionisanju [22].

\section{INTERNET STVARI}

Internet stvari (engl. Internet of Things, IoT) predstavlja vezu raznovrsnih uređaja (drugačijih od standardnih proizvoda poput računara i pametnih telefona) i internet, a ova veza dovodi do procesa transformacije brojnih oblasti u našem svakodnevnom životu [23]. Inicijativa globalnih standarda o internetu stvari (Global Standards Initiative on Internet of Things) definisala je Internet stvari kao "globalnu infrastrukturu informatičkog društva koja omogućava napredne usluge (fizičkim i virtualnim) umrežavanjem stvari, pritom se zasnivajući na postojećim i interoperabilnim informacionim i komunikacionim tehnologijama u razvoju" [24]. Internet stvari omogućava međusobno umrežavanje fizičkih stvari (objekata, vozila, uređaja) sa ugrađenim softverom, senzorima, elektronikom i sl. i neometanu razmenu podataka između njih samih i/ili proizvođača, operatera itd. [25]. Stvari u ovom slučaju predstavljaju bilo koji fizički opipljiv predmet kome može biti dodeljena IP adresa i data mu mogućnost da šalje određene podatke putem interneta.

Internet stvari označavaju globalnu mrežu koja služi da se povežu uređaji i/ili objekti i koja omogućava komunikaciju između samih povezanih elemenata, elemenata i okruženja i sl. [26]. Ova koncepcija takođe, pruža mogućnost povezivanja većeg broja korisnika, uređaja, servisa i aplikacija na Internetu. Međusobno povezani elementi direktno ili indirektno vrše razmenu podataka. Podaci koji su se prikupili obrađuju se ili šalju na obradu u servere ili aplikacije u "oblaku", što nazivamo Cloud computing. Putem mobilnih aplikacija ili samog Interneta korisnici mogu dobiti pristup takvim podacima, podešavanjima i konfiguraciji uređaja, i na taj način mogu da upravljaju sistemima Interneta stvari [27]. Prema statističkim podacima iz 2010. godine broj uređaja koji su spojeni na Internet je iznosio oko 12,5 milijardi, dok je 2014. godine iznosio 25 milijardi. Do 2020. godine se predviđa porast koji će da iznosi oko 50 milijardi povezanih uređaja. Takođe se očekuje da će se IoT povećati na preko 200 milijardi uređaja u 2020. godini [28].

Osnovne karakteristike sistema koji se baziraju na Internetu stvari su [26]: (1) sve komunicira: povezani 
uređaji imaju mogućnost međusobne bežične komunikacije; (2) sve se identifikuje: smart uređaji se identifikuju preko digitalnog imena; i (3) sve interreaguje: smart uređaji mogu da ostvare interakciju sa okruženjem.

Ključna ideja Interneta stvari su komunikacioni interfejsi (npr. Bluetooth Low Energy - BLE, WiFi ili LongTerm Evolution - LTE) koji su integrisani u uređaje koji nisu primarno komunikacijski korisnički interfejs (npr. trekeri ličnih aktivnosti, kućni aparati, ekosenzori i sl.). Sa aspekta korisnika oblasti primene Interneta stvari mogu biti podeljene u tri grupe: (1) IoT za ličnu upotrebu (telesna merenja), (2) IoT za ambijentalnu upotrebu (soba, hotel, kuća, muzej i sl.) i (3) IoT za upotrebu u okruženju (grad, destinacija) [29].

U Tesla automobilima ugrađeni su senzori koji omogućavaju preventivno održavanje i dijagnostiku problema, što povećava sigurnost korisnika. Pomoću Interneta stvari povezani su automobil, pametni telefon vlasnika i fabrika. Automobil putem SMS poruke informiše vlasnika i fabriku o potencijalnom kvaru. Takođe, ova tehnologija ima primenu i u tzv. pametnom parkiranju (primenjuje se npr. u San Francisku, a pilot projekat je razvijen u Novom Sadu) koje omogućava razmenu infomacija o slobodnom parking mestu tokom vožnje u realnom vremenu, što omogućava uštedu goriva i vremena, a smanjuje i gužvu u saobraćaju " [30].

\section{PRIMENA INTERNETA STVARI U TURIZMU}

Internet stvari predstavlja širok koncept povezanosti uređaja i rešenja na osnovu podataka koje pružaju [31]. Ovo je relativno nova oblast tehnologije, tako da je njena primena u turizmu za sad još uvek retka, međutim, potencijali su veoma veliki, posebno jer Internet stvari može pružiti nova i poboljšati postojeća rešenja u procesu kreiranja turističkih usluga.

Pustišek et al. (2014) navode da primena Interneta stvari u turizmu može da se ogleda u sledećem: (1) Lično wellness praćenje - senzori omogućavaju trenutno praćenje različitih aspekata lica, fizičke aktivnosti, praćenje fizioloških parametara kao što su srčani ritam, telesna temperatura, nivo šećera u krvi, kiseonik, ali čak i nivo stresa, količinu i kvalitet spavanja. Iako je većina ovih senzora ugrađeno u mobilne telefone, postoje parametri koji se ne mogu meriti na taj način, te su u te svrhe osmišljeni posebni predmeti (nakit, garderoba, obuća); (2) pametne zgrade - u takvim rešenjima senzori prate okolinu, uključujući npr. temperaturu, osvetljenje i kvalitet vazduha; uobičajeni primer ovakvog pristupa su razni sistemi kontrole i upravljanja pametnim kućama ili zgradama koje omogućavaju daljinsku i automatsku kontrolu grejanja, klimatizacije, ventilacije, osvetljenja okoline. Upravljački interfejsi mogu biti posvećeni korisničkim terminalima u prostorijama, ili mobilnim i Veb aplikacijama dostupnim lokalno i / ili daljinski, često su integrisani sa kućnim multimedijalnim i zabavnim sistemima, kako bi osigurali kompletno korisničko iskustvo u interakciji sa inteligentnim ambijentom. Rešenja za pametne zgrade se često primenjuju u hotelima, ne samo da bi pružili klijentu bolje iskustvo i dodatne usluge, već i smanjili operativne troškove; i (3) pametni gradovi - koncept koji ima za cilj održivost u smislu društvenih, ekonomskih i ekoloških prednosti grada i građana putem rešenja koja omogućavaju IKT. Područja primene najčešće se odnose na povezanost, okruženje, redukciju $\mathrm{CO} 2$, upravljanje saobraćajem, infrastrukturu, inteligentno osvetljenje, smanjenje potrošnje energije, alternativne izvore energije i druge [29].

U cilju približavanja i razumevanja korišćenja Interneta stvari u oblasti turizma i hotelijerstva, Mimos Berhad (2014) ističe sledeće mogućnosti:

- Istraživanje novih iskustava - Geolokacijske tehnologije koje prate gde se turisti nalaze i informacije koje mogu da obogate iskustvo tokom putovanja su veoma traženi od strane proizvođača gedžeta. Sveobuhvatni uređaji Interneta stvari pomažu turistima da snimaju, odnosno beleže vreme, brzinu, rastojanje, lokaciju, nadmorsku visinu i omogućavaju im trenutnu komunikaciju sa drugim turistima koji su se prijavili na istoj lokaciji. Koristeći Internet stvari, pretraga informacija o iskustvima na putovanju će omogućiti turističkiim agencijama i turoperatorima da kreiraju aranžmane koji više odgovaraju potrebama turista. S druge strane, pojedinci mogu učestvovati u avanturističkim ili ekstremnim sportovima kao što su skijanje, ronjenje, planinarenje i drugim aktivnostima koje uključuju elemente opasnosti, te zahtevaju napredne veštine. Upotrebom Interneta stvari koji mogu da "osete" ljudske faktore i faktore okoline, može se smanjiti opasnost avanturističkih sportova, a povećati uživanje u istim [32].

- Medicinski turizam - Koristeći tehnologije Interneta stvari, zdravstveno stanje turista -pacijenata može da se nadgleda daljinski i kontinuirano, kako tokom samog boravka u destinaciji, tokom tretmana, tako i nakon istog. Faza nakon 
tretmana može da obuhvati i pružanje medicinske pomoći pomoću telekomunikacija i druge vidove podrške. Podaci prikupljeni na ovaj način mogu da utiču na: povećanje konkurentnosti pojedinačnih destinacija i preduzeća u medicinskom turizmu, stvaranje pouzdanih i validnih statističkih izveštaja o kvalitetu, bezbednosti i uspešnosti procedura i usluga i sl. [32].

- Ekoturizam - Koristeći sveobuhvatne uređaje Interneta stvari, ekoturističke destinacije mogu biti kvantifikovane kroz direktno merenje i uključene $\mathrm{u}$ interakcije na društvenim mrežama što može da poveća njenu atraktivnost. Takođe, mogu da se angažuju stručnjaci iz oblasti zaštite životne sredine i komunikacija u cilju kreiranja takozvanih e-vodiča ili e-rendžera koji će ponuditi jedinstveno iskustvo i aktivnosti i koji će učiniti usluge personalizovanijim. Upravo ove usluge sa dodatnom vrednošću mogu biti veoma značajne za obogaćivanje interaktivnosti, a destinaciju mogu učiniti važnijim i vrednijim za turiste [32].

- Carinske usluge - U slučaju višestrukog ulaska ili izlaska iz zemlje, komunikacioni terminali mogu biti povezani pomoću Interneta stvari, što umnogome može da olakša obradu, analizu i obradu podataka o više putnika u isto vreme. Ovo može da doprinese automatizaciji razmene informacija između terminala, kao i da spreči nastanak bilo kakve greške. Za putnike upotreba Interneta stvari u ove svrhe može da utiče na olakšavanje i ubrzanje procesa carinjenja $\mathrm{i} / \mathrm{ili}$ verifikacije u slučajevima propuštenih letova, kraćih tranzita i boravka na aerodromu [32].

- Pomoć u donošenju odluka o izboru turističke destinacije - Sa interaktivnim rešenjima za mobilnost, turističke destinacije mogu kroz virtuelne ture ponuditi potencijalnim turistima "privremena iskustva". Naime, posredstvom poboljšane tehnogolije stvarnosti, turistima može biti omogućeno da virtualno obiđu destinaciju i njene lokalitete i da putem interakcije na osnovu gejmifikacije donesu konačnu odluku [32].

- Virtualni konsijerž - Internet stvari u ovom slučaju mogu da ponude personalizovane i prilagođene usluge turistima. Na primer, to može biti rezervisanje željene sobe na određenom spratu, opremljene prema preferencijama gosta, sa izabranom muzikom, nivoom osvetljenja, pićem dobrodošlice i drugim dodatnim uslugama [32].
- Zdravstvena zaštita tokom putovanja - Nadgledanje bolesti povezanih sa putovanjem je suštinska komponenta globalnog javnog zdravlja. Tehnologije Interneta stvari mogu olakšati praćenje zaraznih bolesti i mogu usmeravati i odvojiti turiste koji su zaraženi, dok nadležne službe lakše mogu pružati zdravstvene usluge, kao i blagovremeno reagovati pre nastanka potencijalnih epidemija [32].

\section{ZAKLJUČAK}

Ovaj rad je pokušao da pruži uvid u koncepciju smart turizma, a posebno primene Interneta stvari kao jedne od tehnologija čija se veća upotreba očekuje u budućnosti. Smart turizam se brzo razvija zbog primene i ulaganja u tehnologije. Međutim, sistematična koordinacija i deljenje, kao i eksploatacija turističkih podataka za stvaranje dodatnih vrednosti, još uvek je u razvoju. Prednosti uvođenja tehnologije i Interneta u tradicionalne poslovne modele su mnogobrojne. Zahvaljujući konceptu Big data i Interneta stvari može se postaviti mreža pametnih uređaja i objekata koji mogu poboljšati funkcionisanje bilo koje delatnosti i preduzeća koja posluju u okviru nje. Takođe, rezultati u pogledu poboljšanja turističkih iskustava su očigledni, iako postoji zabrinutost zbog privatnosti ličnih podataka koje generišu pametni uređaji. Ukoliko se preduzmu odgovarajuće mere, ideja smart turizma može doneti velike koristi kako učesnicima na strani ponude, tako i samim turistima.

\section{LITERATURA}

[1] L. Atzori, A. Iera, G. Morabito. The internet of things: a survey. Computer Networks, 54(15), 2010, pp. 2787-2805. doi:10.1016/ j.comnet.2010.05.010

[2] F. Nachira, P. Dini, A. Nicolai, M. Le Louarn, L. Rivera Lèon. (eds) Digital Business Ecosystems: The Results and the Perspectives of the Digital Business Ecosystem Research and Development Activities in FP6. Office for Official Publications of the European Community, Luxembourg, 2007, http://www. digital-ecosystems.org/book/Section0.pdf

[3] R. Živković. Ponašanje i zaštita potrošača u turizmu, Univerzitet Singidunum, Beograd, 2011, pp. 13.

[4] M. Soteriades, and V. Avgeli, V. Promoting tourism destinations: A strategic marketing approach. Tourism Review, 55(3), 2007, pp. 335-345. UDC: 338.487:659.1 
[5] U. Gretzel. Intelligent systems in tourism: A social science perspective. Annals of Tourism Research, 38(3), 2011, pp. 757-779. https://doi.org/10.1016/j. annals.2011.04.014

[6] https://www.statista.com/statistics/273018/numberof-internet-users-worldwide/

[7] A. Njeguš. Informacioni sistemi u turističkom poslovanju, Univerzitet Beograd, 2010, pp. 221.

[8] B. Pan, Z. Xiang, R. Law, D.R. Fesenmaier, The Dynamics of Search Engine Marketing for Tourist Destinations, Journal of travel research 50(4), 2011, pp. 365-377. https://doi.org/10.1177/0047287510369558

[9] D. Buhalis, M. Foerste, Socomo Marketing for Travel and Tourism: Empowering Co-Creation of Value, Journal of Destination Marketing \& Management, 4(3), 2015, pp. 151-161. https://doi.org/10.1016/j. jdmm.2015.04.001

[10] Z. Xiang, D. Wang, J.T. O'Leary, D.R. Fesenmaier, Adapting to the Internet: Trends in Travelers' Use of the Web for Trip Planning, Journal of travel research, 2014, pp. 1-17. https://doi. org/10.1177/0047287514522883

[11] Buhalis, D.; Amaranggana, A. Smart tourism destinations. In Information and Communication Technologies in Tourism 2014; Springer: Cham, Switzerland, 2013; pp. 553-564.

[12] Gretzel, U.; Sigala, M.; Xiang, Z.; Koo, C. Smart tourism: Foundations and developments. Electronic Markets, 2015, 25, 179-188. DOI 10.1007/s12525015-0196-8

[13] C. Koo, U. Gretzel, W. C. Hunter, N. Chung. The role of IT in tourism. Asia Pacific Journal of Information Systems, 25(1), 2015, pp. 99-104. http:// dx.doi.org/10.14329/apjis.2015.25.1.099

[14] W. C. Hunter, N. Chung, U. Gretzel, C. Koo. Constructivist research in smart tourism. Asia Pacific Journal of Information Systems, 25(1), 2015, pp. 105120. http://dx.doi.org/10.14329/apjis.2015.25.1.105

[15] Z. Xiang, V.P. Magnini, D.R. Fesenmaier, Information Technology and Consumer Behavior in Travel and Tourism: Insights from Travel Planning Using the Internet, Journal of Retailing and Consumer Services 22, 2015, pp. 244-249. https://doi. org/10.1016/j.jretconser.2014.08.005

[16] P. Björk, H. Kauppinen-Räisänen, Contemporary Insights to the Dynamic Pre-Trip Information Sourcing Behaviour, Tourism and Hospitality Research 15(1), 2015, pp. 39-53. https://doi. org/10.1177/1467358414553871

[17] W.W. Smith, X. Li, B. Pan, M. Witte, S.T. Doherty, Tracking Destination Image across the Trip Experience with Smartphone Technology, Tourism Management, 48, 2015, pp. 113-122. https://doi. org/10.1016/j.tourman.2014.04.010
[18] Y. Li, C. Hu, C. Huang, L. Duan, The concept of smart tourism in the context of tourism information services, Tourism Management, 58, 2017, pp. 1-8, https://doi.org/10.1016/j.tourman.2016.03.014

[19] J. E. Dickinson, K. Ghali, T. Cherrett, C. Speed, N. Davies, S. Norgate. Tourism and the smartphone app: Capabilities, emerging practice and scope in the travel domain. Current Issues in Tourism, 17(1), 2014, pp. 84-101. https://doi.org/10.1080/1368350 0.2012 .718323

[20] D. Wang, Z. Xiang, D.R. Fesenmaier. Smartphone use in everyday life and travel. Journal of Travel Research, 55(1), 2016, pp. 52-63. https://doi. org/10.1177/0047287514535847

[21] J. Manuyika, M. Chui, B. Brown, J. Bughin, R. Dobbs, C. Roxburgh, A. Hung Byers, Big data: The next frontier for innovation, competition and productivity, McKinsey Global Institute, 2011. https:// www.mckinsey.com/ /media/McKinsey/Business\%20Functions/McKinsey\%20Digital/Our\%20 Insights/Big\%20data\%20The\%20next\%20frontier\%20for\%20innovation/MGI_big_data_exec_ summary.ashx

[22] A. Njeguš, V. Jovanović, M. Veinović, Izazovi i mogućnosti primene analitike velikih podataka u hotelskom poslovanju, Poslovno udruženje hotelsko ugostiteljske privrede Srbije- HORES, 2015.

[23] D. Radaković, D. Cvetković, Z. Radaković, S. Stanojković, S. Trajković, Potencijalne mogućnosti primene Interneta stvari u obrazovanju, Sinteza 2017, International Scientific Conference On Information Technology And Data Related Research, Belgrade, 2017. pp.264-269. DOI: 10.15308/Sinteza-2017-264-269

[24] https://www.itu.int/en/ITU-T/gsi/iot/Pages/default. aspx

[25] https://www.linux.com/news/who-needs-internetthings

[26] V. Vujović, M. Maksimović, G. Balotić, P. Mlinarević. Internet stvari - tehnički i ekonomski aspekti primjene. INFOTEH-JAHORINA Vol. 14, 2015, pp. 658-663.

[27] B. Radenković, M. Despotović-Zrakić, Z. Bogdanović, D. Barać, A. Labus, Ž. Bojović. Internet inteligentnih uređaja, Fakultet organizacionih nauka, Beograd, 2017, pp. 3.

[28] D. Evans. The Internet of Things; How the Next Evolution of the Internet is Changing Everything, White Paper, CISCO Internet Business Solutions Group, 2011, pp. 3. https://www.cisco.com/c/dam/en_us/ about/ac79/docs/innov/IoT_IBSG_0411FINAL.pdf

[29] M. Pustišek, L. Mali, A. Kos, Scopes in Internet of Things for Active Tourism and Leisure, ERK'2014, Portorož, pp:85-88, 2014, http://erk.fe.uni-lj. si/2014/pustisek(scopes)p.pdf 
[30] http://www.erpsusreti.rs/prezentacije/p4.pdf

[31] D. Miorandi, S. Sicari, F. De Pellegrini, I. Chlamtac. Internet of Things: Vision, applications and research challenges, Ad Hoc Networks, 10 (7), 2012, pp. 14971516. https://doi.org/10.1016/j.adhoc.2012.02.016
[32] Mimos Berhad, IoT Idea Book, Kuala Lumpur, Malaysia, 2014.

[33] K. Kaur, R. Kaur, Internet of Things to promote Tourism: An insight into Smart Tourism. International Journal of Recent Trends in Engineering \& Research, 2016, pp. 357-361. 